\title{
Reconstruction of Village Landscape Based on the Characteristics of Ethnic Culture -- Taking Zhenshan Village in Huaxi District as an Example
}

\author{
Wang Meng ${ }^{1, *}$, Wang Hong ${ }^{2}$ \\ ${ }^{1}$ Forestry College, Guizhou University, Guiyang, China \\ ${ }^{2}$ School of Architecture and Urban Planning, Guizhou University, Guiyang, China \\ Email address: \\ 1161983069@qq.com (Wang Meng), wanghong1960@126.com (Wang Hong) \\ ${ }^{*}$ Corresponding author
}

To cite this article:

Wang Meng, Wang Hong. Reconstruction of Village Landscape Based on the Characteristics of Ethnic Culture -- Taking Zhenshan Village in Huaxi District as an Example. Science Discovery. Vol. 5, No. 5, 2017, pp. 399-403. doi: 10.11648/j.sd.20170505.26

Received: August 2, 2017; Accepted: August 14, 2017; Published: September 18, 2017

\begin{abstract}
With the gradual improvement of the living standard, also place the new rural construction, village landscape are not so good, however, in this paper, based on the research on guiyang Huaxi Town mountain village buie minority village, village landscape restoration by national culture means reshaping, let the village landscape unique, comfort, and explore a suitable for different from the conventional development new way to protect the ancient landscape, looking for a combination of visual landscape with the landscape characteristics of village landscape plan.
\end{abstract}

Keywords: Village Landscape, National Culture, Landscape Restoration, Landscape Reconstruction, Visual Landscape

\section{基于民族文化特点下的村落景观视觉重塑——花溪区镇山村例}

王龙 ${ }^{*}$, 王红 ${ }^{2}$

${ }^{1}$ 林学院, 贵州大学, 贵阳, 中国

建筑与城市规划学院, 贵州大学, 贵阳, 中国

邮箱

1161983069@qq.com（王龙）, wanghong1960@126.com（王红）

摘要: 随着生活水平的逐步提高, 新农村建设也紧锣密鼓的进行着, 然而村落景观却不尽人意, 本文基于对贵阳花溪 镇山村布依少数民族村落研究, 利用民族文化手段进行村落景观修复重塑, 让村落景观具有独特性、舒适性, 探索一 条有别于常规开发保护古镇景观的新路子，找寻一条视觉景观同景观特色相结合的村落景观方案。

关键词: 村落景观, 民族文化, 景观修复, 景观重塑, 视觉景观

\section{1. 引言}

在建设新农村这个大环境下, 越来越多的农村建筑得 以改善, 许多农村建筑将砖墙再次粉刷, 屋顶也将砖石换 成瓦片甚至改变了屋顶原有结构, 可是盲目的借鉴、盲目
的推广使得新农村建设出现了千城一面的现象 [1], 因此科 学地学习了解当地民族文化以及人文特征对村落整体景 观布局以及景观舒适度都有很重要的影响。建筑是一种不 可复制的历史记忆, 然而村落景观则是历史长河中的一张 名片, 将文化注入建筑, 让建筑影响生活, 本文以花溪镇 
山村布依族少数民族村落为例, 将贵州传统少数民族文化 融入村落景观中, 从而再塑景观视觉的民族定义。

\section{2. 研究背景}

花溪镇山村地处贵州省贵阳市南部，拥有得天独厚的 自然资源以及区位优势，环山面水，形成负阴抱阳之势， 气候冬暖夏凉, 雨水丰足。全村共有布依族 105 户，苗族 38 户, 汉族 1 户, 以布依族为主。以屯墙为界, 分上下两寨, 共 $4.1 \mathrm{hm}^{2}[2]$, 由一条南北主干道串联, 并由多个东西走向 支线进行分流。镇山村拥有丰富的旅游资源以及深厚的人 文底蕴, 可是并不突出的村落景观导致镇山村的知名度并 非如同它的历史一样, 浑厚出彩。随着汉文化的入侵, 镇 山村的布依文化逐渐弱化, 凌乱的村居道路也妨碍了村落 景观的舒适度，因此，重塑布依民族文化下的村落景观是 目前镇山村的首要目标。

\section{3. 布依文化的延续}

\section{1. 图腾文化}

在镇山村布依村寨建筑各处均可看到大小不一的图 腾, 或具有装饰效果或有一种特殊意义, 不少布依族居民 在自家民居的门檐、栏杆、门框、庭院桌柱脚等位置绘制 雕刻图案, 常以龙风图案为主, 代表了当时人们祈求风调 雨顺的思想 [3]。布依族是一个勤劳的少数民族, 背山而筑 面水而居, 因此牛的身影也常常出现在他们的生活当中, 被村民们当做守护神, 保佑家族的平安。布依人的服饰精 美绚烂, 上面的图案也尤为精细, 不少服饰上面均以鱼形 图案来绘制, 代表了当地居民民祈求幸福安康, 吉祥如意 的美好愿望。不管是建筑上的图腾还是生活中的图腾, 布 依人用自己的智慧创造出了属于他们自己的精神财富以 及对未来美好生活的向往, 然而特殊的图案标志也成为了 布依人久久不能舍弃的文化财富。（如图1）

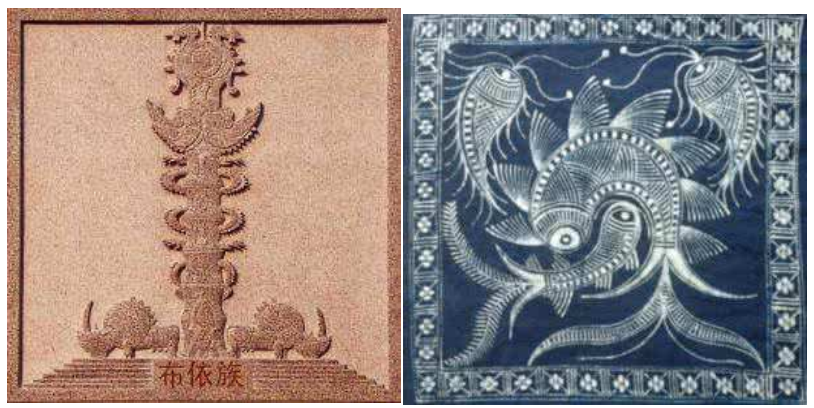

图1 布依族图腾文化。

\section{2. 建材文化}

现在贵州省的布依族主要分布在黔南、黔西南两个布 依族苗族自治州、安顺地区的镇宁、关岭两布依族苗族自 治县和紫云苗族布依族自治县以及贵阳、六盘水两市的周 边地区 [4]。建材的选择成为构筑建筑的首要考量, 在古时 候, 聪明的布依人利用大自然的馈赠搭建了两种房屋材 质, 一种为全木结构, 一种为下木上石板构造, 然而镇山
村的绝大多数民居都属于下木上石材质, 由于木材承重效 果并不乐观，因此镇山村民选用质量较高、耐腐蚀的杉木 作为建筑主体结构的承重, 梁柱通过榫卯相接, 增强其稳 定性。镇山村地处贵州黔中腹地, 石漠化程度高, 地表侵 蚀严重, 属于典型的喀斯特地貌, 土壤流失导致岩石裸露, 经历了上亿年的风化侵蚀形成了当地独有的页岩, 当地布 依人就地取材, 利用页岩轻薄等物理特性, 将屋顶石片错 位相接, 以石板当瓦片, 打造独有贵州黔中布依特色的建 筑“石板房”[5]。（如图2）

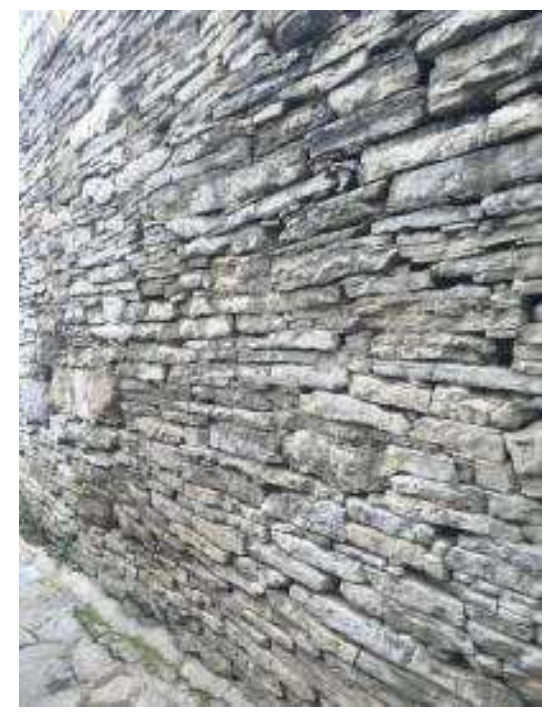

图2 建筑石材。

\section{3. 建筑文化}

建筑的发展经历了几个时期，《易经. 系辞》曰: “上 古穴居而野处”, 从开始的穴居以防猛兽, 到之后《韩非 子.五冨》中曾提到: “上古之世，人民少而禽兽众，人民 不胜禽兽虫蛇, 有圣人作, 构木为巢, 以避群害的巢居[6], 人们的生活品质正因需求的发展, 开始逐渐发展建筑文 化, 形成了半干栏式建筑与干栏式建筑, 例如镇山村的布 依居民民居则是依山而建傍水而居, 依山是为了借地势造 干栏建筑, 傍水是因为稻作农耕生产对水源灌溉的依赖 [7], 因为生活需要, 布依人多选择此地形作为村落地址, 因为取材状况, 布依人选取木石相结合的构建手法修筑建 筑。（如图 3)

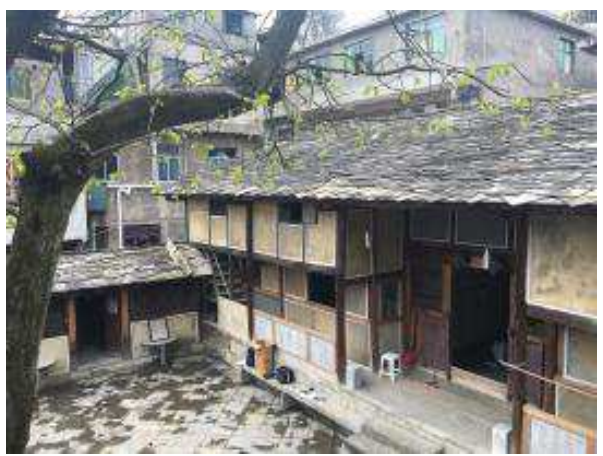

图3 石板房。 
古时候的布依族没有那么先进的科技以及那么多的 建材选择, 他们利用自己的聪明才智, 合理的选择地形, 因需所筑, 因利而生, 在建材的选取上也秉持就地取材因 地制宜的策略进行房屋的搭建, 正确运用材质的物理属性 进行建筑功能上的建设, 将心中的美好化作图腾得以表 达, 利用古朴纯粹的建筑方式, 使我们知道了镇山村布依 居民的独特村落景观。

\section{4. 布依族镇山村景观重塑}

镇山村的整体布局我分为三个层面, 第一是局部景观 塑造, 明确村落的代表人群以及重塑方向, 增强局部景观 的民族特征; 第二是整体布局的合理化, 以点连线, 以线 画面的方法将镇山村分为三大区域, 增强空间的连续性; 第三是线性空间 (道路) 的舒适化重塑, 利用建筑与道路 的高宽比进行视野以及体感的舒适性改造, 极富有视觉性 又具舒适性。

重塑镇山村村镇景观有着得天独厚的优势, 首先是民 族地域性，全村百分之七十五均为布依村民，拥有独特的 喀斯特地貌上, 为建筑的精细化加工做出了贡献, 其次是 自然资源丰富性, 拥有丰富的水资源 (花溪水库) 以及木 材 (杉木) 石材 (页岩) 资源, 为景观提供了原生态的自 然资源。基于此, 为镇山村村落景观重塑奠定了可行性与 可观性。

\section{1. 局部景观塑造}

\subsection{1. 总体平面}

镇山村分上下寨, 以一条南北主干道贯穿始末, 整体 形态单一, 固有景点零散, 可观性不强。因此可在固有景 点上另增中心广场、一线天、排房景观、酒吧等景观, 将 零散的区域布局规整化, 有利于加强村落区域之间的联 系。（如图4）

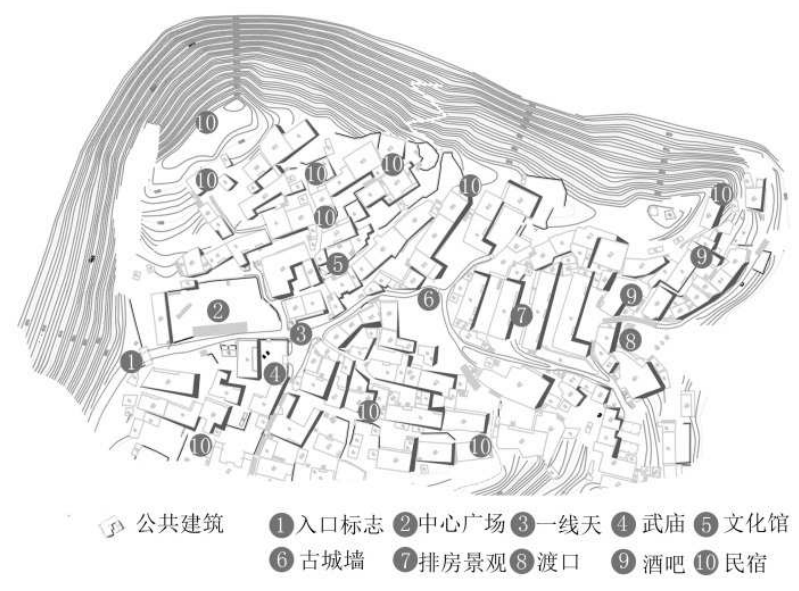

图4 镇山村总平图。

4.1.2. 代表景点重塑

1、入口处

寨门是村落最具代表性以及最重要的一个景观节点, 大门合理的运用了大石砌筑, 使大门显得形式较为厚重、
敦实, 然而镇山村的寨门却略显朴素平淡。由于村寨位于 花溪水库上游, 可在寨门两侧以巨石堆砌“龙头风尾”, 以 水车引渠注水, 在龙头前形成一条水景, 可赋予村落“有 水而穿”的神韵。

\section{2、交叉空间}

节点6古城墙为上下寨分界的交叉节点, 处于村落的 中部, 在村落中起到承上启下的作用。

洞口与前路形成“十字”交叉结构, 由于镇山村本来的 定位是军事屯堡, 因此在景观效应上并不过多关注, 本着 遵循初原也可改善景观效应的原则对分界城墙进行景观 装饰, 由于城墙所建位置相对平坦开阔, 向下便是花溪水 库, 可在植物较少的镇山村城墙前方种植杉树, 形成视野 线, 城门与前方形成框景, 规范种植的树木也可在十字交 叉的通道上形成通风廊道, 在人体舒适度上也有很大的提 高, 布依族是一个能歌善舞的少数民族, 比较出名的乐器 有铜鼓、姊妹箫、尤勒等, 且制作工艺精湛, 可在城墙背 面放置铜锣, 以此作为民族小品。（如图5）

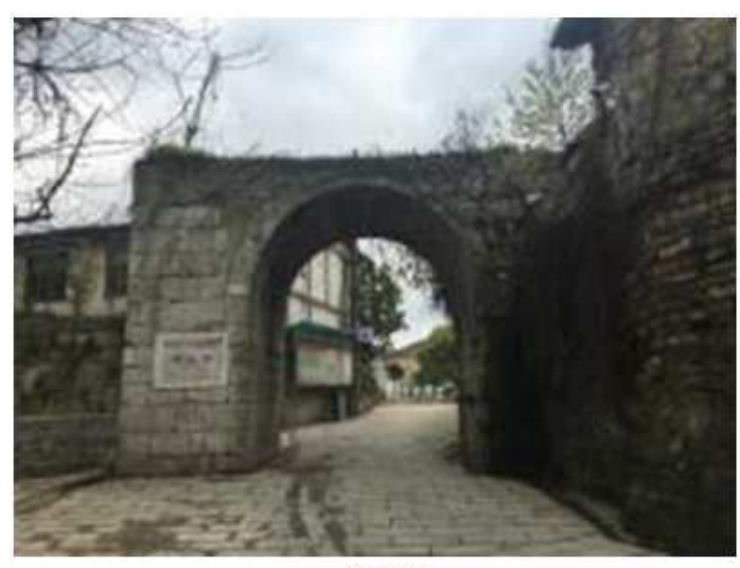

1 人口处

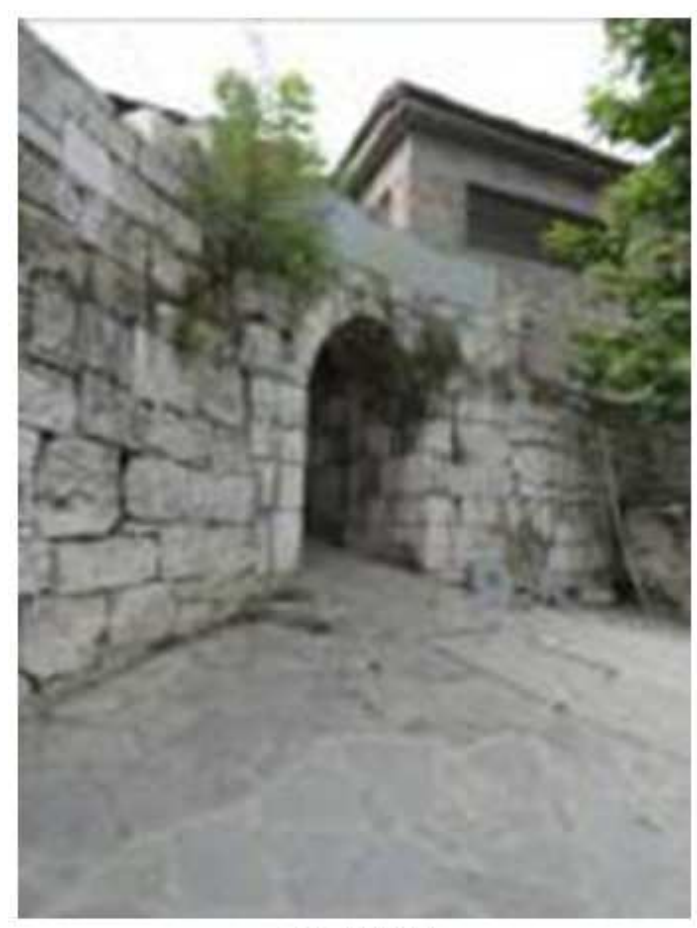

2 交叉空间 


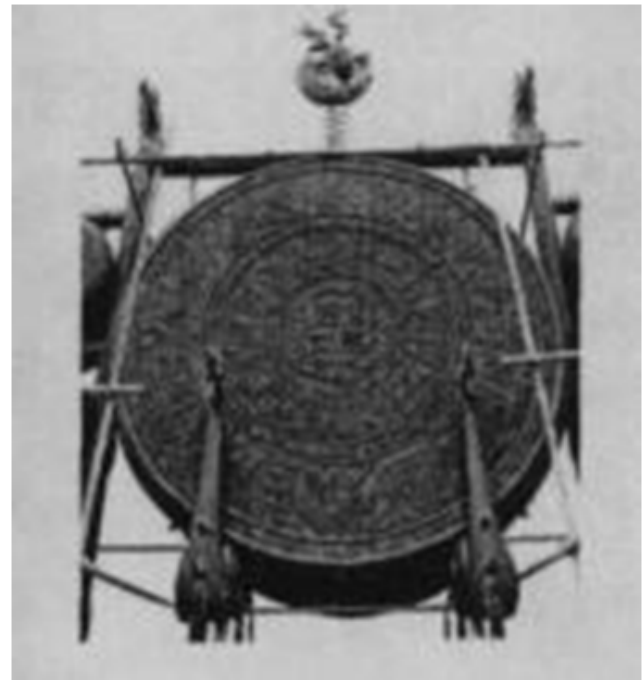

3 铜锣

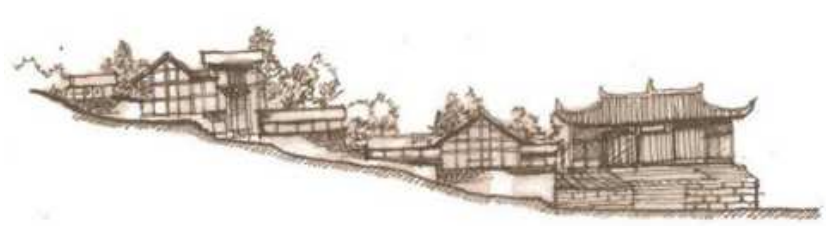

4 内城门外侧坡下空间

图5 代表景点。

\section{2. 整体布局重塑}

目前的镇山村景点少, 结构零散单一, 功能层次低, 现将镇山村分为三个区域:民族文化区、休闲娱乐区、住 宿接待区, 这样不仅在功能上更加完善镇山村发展体制, 又能更好的促进当地旅游业的发展, 在视觉上也不显得零 散无章法, 形成一主二辅结构。（如图6）

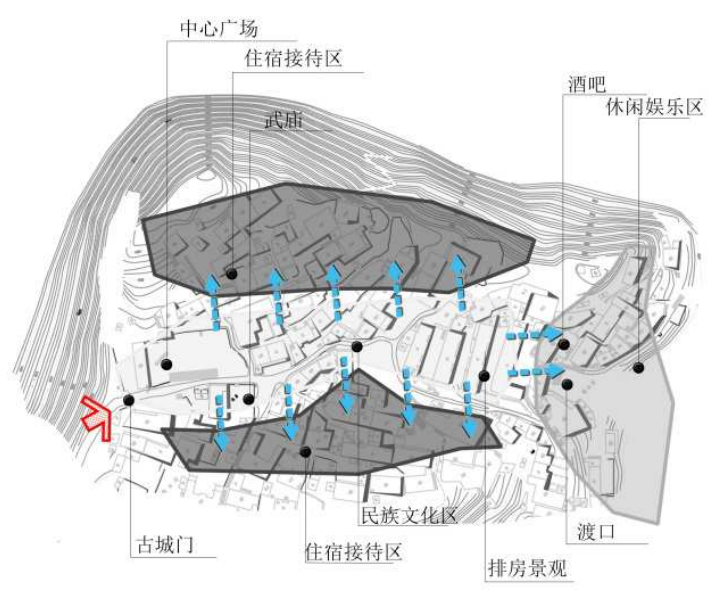

图6 镇山村功能分区图。

\section{3. 线性空间的舒适度重塑}

镇山村是由一条主干道多条次级道路组成, 道路的宽 窄不一, 回旋转折, 时而上坡时而下坡, 犹如历史的长河。
村落的道路基本是由石板铺设而成, 青石板铺设的路面带 给镇山村夏季以凉爽舒适的感觉, 被岁月所渲染的青石已 经日渐光亮, 走在村落当中犹如在感受大自然的鬼斧神 工。利用建筑同街道高 (H) 宽(D)比（表1）[8]与临街铺 面面阔 $(\mathrm{W})$ （表2）[9]的不同对村落主要街道进行视觉重 塑。在一线天景观处, 两侧房屋高度相较街道略大一些, 虽然会有一种视觉上的压迫感, 可是正式由于道路长度并 不算长, 导致一线天景观可以让人们走过之后看到之后景 观的一片豁达, 这又是一种景观心境的体现。然而 $\mathrm{W}$ 的出 现使得街道生气勃勃, 更具村落活力。

表1 镇山村街道 $\mathrm{D} / \mathrm{H}$ 值分析。

\begin{tabular}{|c|c|c|}
\hline $\mathrm{D} / \mathrm{H}<\mathbf{1}$ & $\mathrm{D} / \mathrm{H}=\mathbf{1}$ & $\mathrm{D} / \mathrm{H}>\mathbf{1}$ \\
\hline 产生压抑紧迫感 & 均匀和谐, 舒适感较强 & 距离空间感较大 \\
\hline \multicolumn{3}{|c|}{ 表2 镇山村街道D/W值分析。 } \\
\hline $\mathrm{D} / \mathrm{W}<1$ & $\mathrm{D} / \mathrm{W}=1$ & $\bar{D} / \mathbf{W}>1$ \\
\hline 街道产生急促瓦 & $\begin{array}{l}\text { 街道与周围形成良 } \\
\text { 好氛围, 亲切感 }\end{array}$ & 街道空旷, 冷清 \\
\hline
\end{tabular}

4. 4. 继承、修复、重塑村落景观

\section{4. 1. 继承与发展}

对于镇山村来说, 它犹如沉睡了百年的老者, 不争不 抢, 可是在时代的变迁当中, 四处变得喧闹吵杂, 城市充 斥着钢筋混凝土, 然而镇山村以她独有的民族文化与传统 建材成为现今不可多得的一块历史遗迹, 秉持将文化特色 继承, 传统建材发展, 让其以一种独特的方式回归本源, 回归生活。

\section{4.2. 装饰与修复}

镇山村在岁月以及时代的长河中多多少少的出现了 一些景观上的漏洞, 然而现将建筑景观分为两类, 一类是 保存较为完好的景观, 可采取装饰相对较好的景观, 使他 们锦上添花, 在其立面、色彩选取以及形态尺度方向以民 族文化为蓝本进性风格上的延续, 然而对于那些有破损或 是景观缺失的建筑仅仅指在其外部进性针对性小规模修 复, 使其尽量贴近整体风格。

\subsection{3. 景观重塑}

景观重塑包含两个方面, 一是村落内部建筑的景观重 塑, 利用地形、视野线、天际线、建筑造型、建筑装饰、 建筑小品等内在因素对村落内部进行景观再造, 使村落赋 予层次感、视觉感。第二点往往是被人所忽略的, 事物的 内因往往也因外因而得以升华, 村落周边区域的景致同样 重要, 对周边坏死植物以及水景进行人工种植修复, 对围 墙、石登等一些外部园林小品进行细致刻画, 这样通过里 外相结合, 更加增强了村落的活力。

在小范围的精细化村落景观重塑调整当中, 由于利用 了当地特有的少数民族传统元素以及结合地域性自然资 源的基础上, 打造独特的镇山村布依村落景观, 使村落景 观不仅仅局限于增加覆盖, 而是要懂得如何利用现有优 势, 以镇山村民族村落为例, 为今后民族村落的景观重塑 梳理新思路, 打造不一样的新农村。 


\section{5. 结论}

本文以花溪镇山村为例, 结合镇山村居民的民族特异 性, 对镇山村景观进行了视觉上的修复, 探寻出一条开发 与保护相结合、继承与重塑想结合的村落景观形态新路 子, 从重塑的案例我们可以很清楚的知道, 发展并不是以 为的高科技与高技术, 他要的是一份对故乡的思念, 一份 对留得住乡愁的期盼 [10], 利用现有景观一点画面, 一面 成景的手法进行村落景观修复, 在很大层面上增进了当地 居民的视觉感受, 其次对民族文化也是另一种延续。当然 在景观修复的同时也可以适当地发展当地旅游业, 利用布 依族特有物品、风俗、美食吸引游客, 促进当地经济水平 的发展, 提高人们的生活水平和精神文化水平。希望通过 本文的研究, 可以为全国的村落保护发展提供一些独到的 建议。

\section{参考文献}

[1] 谢志强, 王红艳. 城市建设不能本末倒置——如何规避“千 城一面”现象 $[\mathrm{J}]$. 人民论坛, 2017(15):54-56。
[2] 李乐京, 陈志永, 梁玉华. 贵州镇山村布依族村寨生态旅 游开发研究 $[J]$. 贵阳学院学报 (自然科学版)， 2007 (6): 75-77。

[3] 王媡. 贵州布依族民居建筑文化元素初探 [J]. 西部论坛, 2014 (1):33-34。

[4] 王㜆. 浅议布依族民居建筑类型与构成要素一以贵州为 例 $[J]$. 地情研究, 2014:114-117。

[5] 黎玉洁. 贵州地区布依族民居的生态性研究[J]. 中外建筑, 2015 (6): 60-61。

[6] 韩非子. 韩非子 $[\mathrm{M}]$. 北京: 中华书局, 2010。

[7] 戴艳, 邹雨橙. 坡芽歌书的生活文化解读 $[\mathrm{J}]$. 文山学院学 报，2013(5):1-4。

[8] 魏柯. 四川古镇街道空间文化价值解析 $[\mathrm{J}]$. 西南民族大学 学报（人文社科版），2011，32 (9): 149-152。

[9] 金湛林. 贵州青岩古镇及其建筑探析[D]. 重庆大学, 2004,12: 42-43。

[10] 刘学. 人民日报观察者说: 农村要留得住“乡愁”[Z]. 人民 网-人民日报，2014。 